\title{
Preparation of Sulfated Zirconia Catalyst Loaded by Copper in 'Nano-scale: Green Application' to Synthesis of Biolubricant
}

\author{
Amina H. Ibrahim*, Hussin Al-Shafey Ismail, Doaa S. El-Desouki, Samira M.Abdel-Azim, \\ Noha A. K. Aboul-Gheit \\ Egyptian Petroleum Research Institute, Cairo, Egypt.
}

$\mathbf{T}$

HIS STUDY investigates the activity of copper-doped catalysts supported on sulfated zirconia (SZ) for the esterification of Free Fatty Acid (FFA). Three catalysts SZ, Cu/SZ (sol) and $\mathrm{Cu} / \mathrm{SZ}$ (imp) were prepared. The latter two catalysts contain $10 \% \mathrm{Cu}$ supported on sulfated zirconia $(\mathrm{Cu} / \mathrm{SZ})$ prepared by wet impregnation $(\mathrm{Cu} / \mathrm{SZ} /(\mathrm{imp}))$ and sol-gel method $(\mathrm{Cu} / \mathrm{SZ} /(\mathrm{sol}))$. The catalysts were characterized by X-ray diffraction (XRD), $\mathrm{NH}_{3}$ Temperature Programmed Desorption (TPD), $\mathrm{N}_{2}$ adsorption, Fourier transform infrared spectroscopy, and imaged by scanning electron microscopy. The XRD analysis showed that, the loading of $\mathrm{Cu}$ in the zirconia structure has stabilized the tetragonal zirconia phase, which is the most active phase. Also, the formation of $\mathrm{Cu}_{2} \mathrm{O}$ and $(\mathrm{CuO}-\mathrm{ZrO})$ composite has been proved for the sol-gel preparation technique. The TPD illustrated that the incorporation of $\mathrm{Cu}$ ions in the lattice of zirconia via sol-gel technique has lowered the acidity of the catalyst much more than impregnation technique. As a green application, different concentrations of the prepared catalysts were used for preparation of biolubricants by direct esterification of FFAs. The $\mathrm{Cu} /$ $\mathrm{SZ} /$ (sol) catalyst has the highest activity. The percentage yields of synthesized biolubricants reached $99.8 \%$ when $0.3 \%$ from the selected catalyst was utilized. Pour point, Flash point, Viscosity index, Apparent Viscosity and Percentage yield values of synthetic ester oils were evaluated.

Keywords: Sulfated zirconium, Biolubricant, Green application, Sol-gel, Free fatty acid.

\begin{abstract}
$\underline{\text { Abbreviations }}$
Proton nuclear magnetic resonance ${ }^{1} \mathrm{HNMR}$; apparent viscosity AV; 'Deuterated chloroform' solution $\mathrm{CDC}_{13} ; 10 \% \mathrm{Cu}$ supported on sulfated zirconia $\mathrm{Cu} / \mathrm{SZ}$; 1-Decanol DA; flash point FP; Fourier transform infrared spectroscopy FTIR; Gel permeation chromatography GPC; metal impregnation method (imp); oleic acid OA; pour point PPT; P-Toluene sulphonic acid monohydrate PTSA; size exclusion chromatography SEC; scanning electron microscopy SEM; sol-gel method (sol); sulfated zirconia SZ; temperature programmed desorption TPD; viscosity index VI; X-ray diffraction XRD.
\end{abstract}

\section{Introduction}

Biolubricants have significant advantages compared with common lubrication products; they are non-toxic and biodegradable $[1,2]$. Using them, it is not necessary to add antioxidants, viscosity index improvers, stabilizers, or detergents [3-5].

In addition, they can lubricate over a wider temperature range because their viscosity does not vary with temperature [6].

The main raw materials for biodegradable lubricants are of vegetable origin. Synthetic biolubricant can be prepared by esterification of free fatty acids (FFAs) derived from vegetable oils; with alcohols in the presence of catalysts. The esterification reactions are commonly catalyzed by acidic based homogenous or heterogeneous catalysts, using principally sulphuric or phosphoric acids. The heterogeneous

\footnotetext{
*Corresponding author e-mail: dr.amina.ibrahim@gmail.com Tel : +2-01001261760 
catalysts are more favorable to overcome many problems facing the homogenous catalysts, like vessel corrosion and catalyst separation [7].

Several solid acid catalysts have been reported to produce esters from vegetable oils [8-13]. In the present work, biolubricants were synthesized from esterification reaction of FFAs and methanol using sulfated zirconia as a heterogeneous catalyst. The surface acidity of SZ is strongly dependent on the crystallographic phase of zirconia. In the sulfated state, tetragonal zirconia exhibits higher surface acidity and catalytic activity than the more stable, monoclinic zirconia. Surface acidity is the determining factor for the initial activity of heterogeneous FFA esterification catalysts $[14,15]$.

The SZ system offers the notable advantage of high selectivity for FFA esterification even in the presence of excess alcohol. The use of excess alcohol in FFA esterification promotes side reactions such as alcohol dehydration (to form dimeric ether). It is known that SZ exhibits a relatively low activity for alcohol dehydration and high selectivity for esterification in the presence of excess alcohol, and is thus suitable as a catalyst for reactive-distillation-assisted FFA esterification, in high alcohol/ acid ratios [16].

A common approach for improving the activity and durability of SZ is forming mixed oxides with other metal oxide components. Jiang, et al. [17] reported significant enhancement of the esterification activity and sulfurleaching resistance of $\mathrm{SO}_{4}^{2-} / \mathrm{ZrO}_{2}$ by forming a homogeneous mixture of oxides $\left(\mathrm{MoO}_{3}-\mathrm{Nd}_{2} \mathrm{O}_{3}\right.$. $\mathrm{MoO}_{3}-\mathrm{Nd}_{2} \mathrm{O}_{3}$ ) species mixed with $\mathrm{ZrO}_{2}$ that stabilize the tetragonal $\mathrm{ZrO}_{2}$ phase.

In the present work, we apply $\mathrm{Cu} / \mathrm{SZ}$ catalysts using Copper as transition metal which is introduced by two different methods, and explain the effect of the introducing method on the acidity, surface area, stability of tetragonal phase and intensities of oxides and sulfates groups in the prepared catalyst and accordingly the conversion percentage of esterification reaction.

\section{Experimental}

\section{Preparation of the catalysts}

The catalysts were prepared using zirconium iso-propoxide $(70 \%)$ purchased from Aldrich Chemicals, Iso-propanol (99\%) and $\mathrm{H}_{2} \mathrm{SO}_{4}$ $(96 \%)$, purchased from Gomhoreya chemicals and Copper acetate, purchased from Merck.

\section{SZ600 catalyst}

Preparation of the catalysts has been carried out according to a modified method [18] by 10 $\mathrm{cm}^{3}$ of zirconium iso-propoxide $(70 \%)$ in 12.5 $\mathrm{cm}^{3}$ iso-propanol $(99 \%)$ was mixed slowly with $0.25 \mathrm{~cm}^{3} \mathrm{H}_{2} \mathrm{SO}_{4}(96 \%)$. The mixture was placed in a conical flask and stirred for $30 \mathrm{~min}$ at room temperature. The weight ratio of $\mathrm{Zr}$ : $\mathrm{S}$ was 1:0.038. A solution of $30 \mathrm{~cm}^{3}$ iso-propanol in 1.6 $\mathrm{cm}^{3} \mathrm{H}_{2} \mathrm{O}$ was added drop-wise with stirring to carry out the hydrolysis and gelation. The gel was aged for $1 \mathrm{hr}$ at room temperature then dried for $12 \mathrm{~h}$ at $120^{\circ} \mathrm{C}$. The end step is calcination in static air at $600{ }^{\circ} \mathrm{C}$ for $3 \mathrm{hrs}$.

\section{$\mathrm{Cu} / \mathrm{SZ} /$ (sol) catalyst}

This catalyst was prepared by the procedure used in preparing SZ catalyst, but there was another addition during the first mixing step, that was the precursor of copper (copper acetate) (Fig.1.a).

\section{$\mathrm{Cu} / \mathrm{SZ} /$ (imp) catalyst}

The prepared SZ600 powder was impregnated in an aqueous solution containing the calculated amount of copper acetate. The paste was then dried at $110{ }^{\circ} \mathrm{C}$ overnight, then subjected to calcination in air at $400^{\circ} \mathrm{C}$ for $3 \mathrm{~h}$. (Fig.1.b)

\section{Synthesis of Ester \\ Materials}

Oleic acid (OA), 1-Decanol (DA) and P-Toluene Sulphonic acid monohydrate (PTSA), were purchased from Aldrich Chemicals, O-xylene was purchased from Aduic Chemicals Company.

\section{Experimental set-up and procedure}

The reaction was carried out in a four-neck glass flask equipped with a stirrer, thermometer, nitrogen gas inlet and a reflux condenser. A mixture of the free fatty acid OA $(0.01 \mathrm{~mol})$, alcohol DA $(0.011 \mathrm{~mol})$, in practice, excessive alcohol is often added since this reaction is reversible, [19], with studied catalyst (0.3-3) wt \%, based on total weight of reactants, was charged in the reactor vessel under $\mathrm{N}_{2}$ gas at $140^{\circ} \mathrm{C}$ for $6 \mathrm{~h}$ in $\mathrm{o}$-xylene as a solvent. The water produced via the esterification reaction was removed throughout the course of the reaction using 'Dean and Stark separator'. At the end of the reaction, the reacting mixture was cooled to room temperature, and the catalyst was separated from the reaction mixture by centrifugation. The reaction was repeated under the same conditions by applying each prepared catalyst in different concentrations (0.3-3) wt $\%$ based on total weight of reactants. 
The collected liquid product was purified and its structure was confirmed by Fourier transform infrared spectroscopy (FTIR) and Proton nuclear

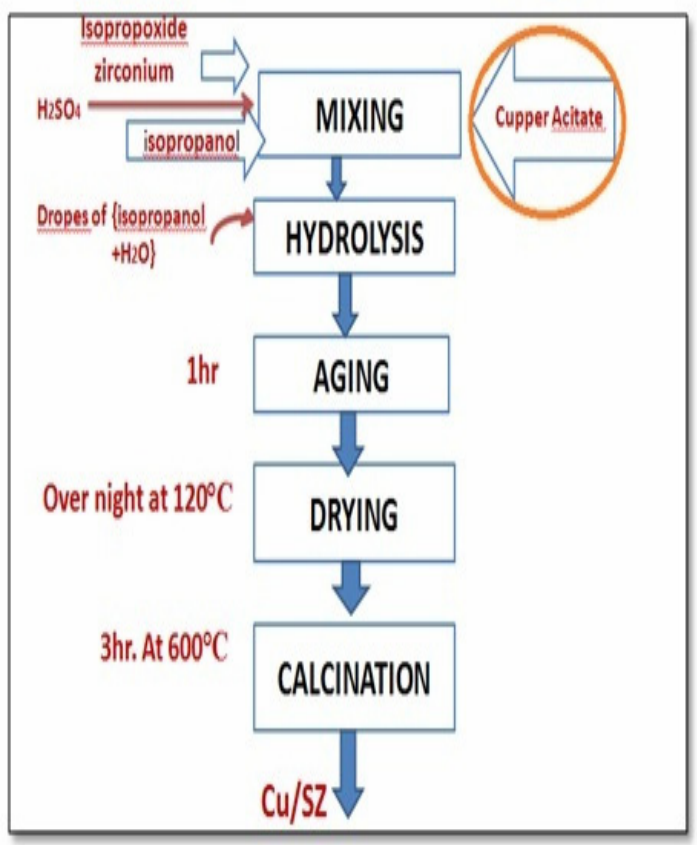

Fig. 1. Flow diagram of catalysts Preparation:

Fig.1.a Cu/SZ (sol)

The esterification reactions require bifunctional catalyst to play the two steps of protonation as the first step and deprotonation as the end step of the mechanism as shown in Fig. magnetic resonance $\left({ }^{1} \mathrm{HNMR}\right)$ spectroscopy. Gel permeation chromatography (GPC) was used to determine the average molecular weight of the prepared esters.

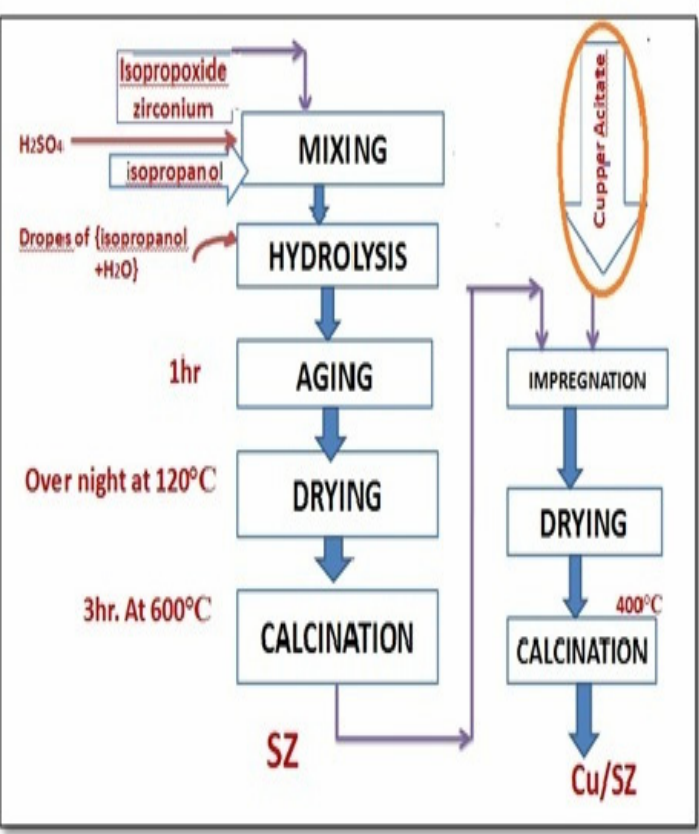

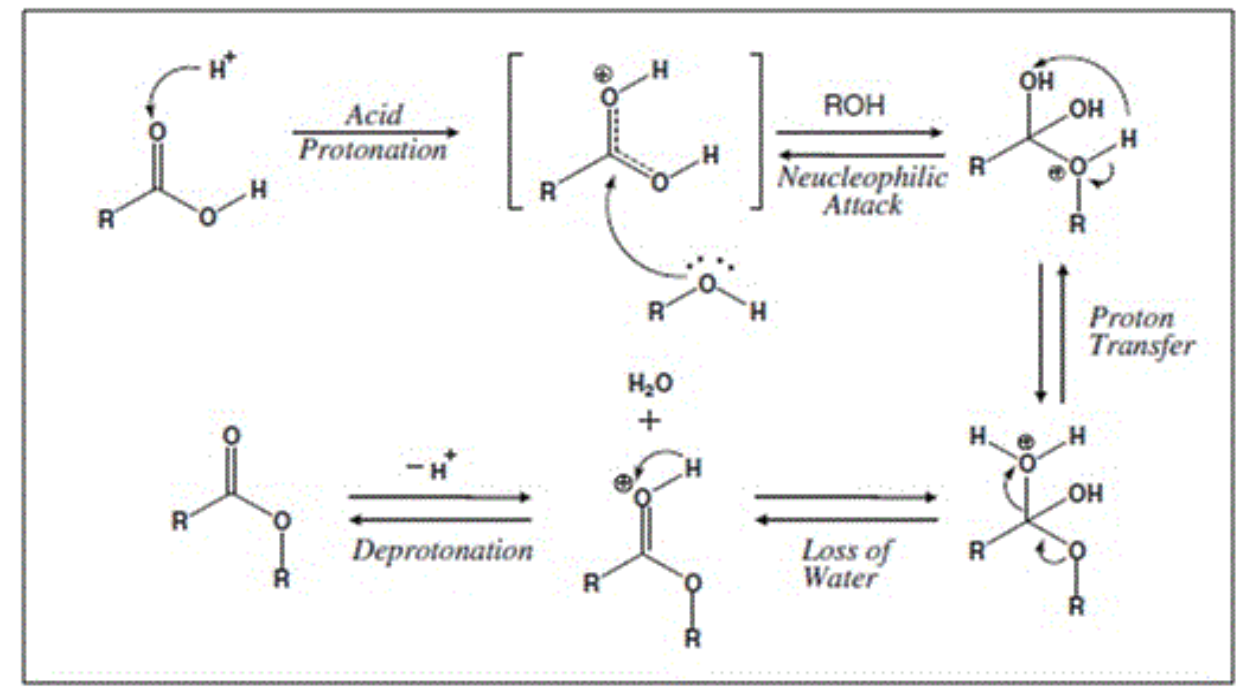

Fig . 2. Mechanism of Esterification [20]. 
Characterization of catalysts and products

Characterization of the Catalysts

$X$-ray diffraction (XRD)

All catalysts were characterized by powder X-ray diffraction (XRD) for crystallinity measurements and oxide content in the solid materials, using analytical $\{$ X0PERT PROMPD $\mathrm{X}$-ray diffractometer, $\mathrm{Cu} \mathrm{Ka}$ radiation of wavelength $\mathrm{k}=1.5406 \mathrm{~A}^{\circ}$, rating of $40 \mathrm{KV}, 40$ $\mathrm{mA}$, step size $=0.02$ and scan step time of $0.4 \mathrm{~s}$.

\section{$\mathrm{NH}_{3}$ Temperature Programmed Desorption} ( $\left.\mathrm{NH}_{3}-\mathrm{TPD}\right)$

The evaluation of the acidity and its strength of the prepared catalysts were achieved by monitoring the amount of the desorbed $\mathrm{NH}_{3}$ from the catalyst surface after exposing to stream of $\mathrm{NH}_{3}$ for a certain period. The experiment involves adsorption of a chosen molecule at a low temperature $\left(\mathrm{T}_{0}\right)$, and then measuring its rate of desorption as the temperature is increased. The temperature $(\mathrm{T})$ is normally increased at a linear rate [21].

Surface analysis

Isothermal nitrogen adsorption/desorption method was used to evaluate the specific surface area and pore size distribution of all prepared catalysts using the BET method. The BJH method was also applied for calculating the pore size and pore radius as well as the internal surface area of the prepared catalysts. These parameters were determined using Quanta chrome Nova 3200, commercial BET unit at $78 \mathrm{~K}$ using liquid $\mathrm{N}_{2}$. Prior to the measurement, the samples were outgassed in a stream of $30 \% \mathrm{~N}_{2} / \mathrm{He}$ mixture while being heated to $200^{\circ} \mathrm{C}$ for $3 \mathrm{~h}$ under a reduced pressure of 10-5 Torr to remove adsorbed moisture from the catalyst surface.

Scanning electron microscopy (SEM)

Scanning electron microscopy (SEM) uses a finely focused beam of electrons in order to produce a high resolution image of a sample. SEM images have a three dimensional appearance, which is very useful while examining the surface structure of a sample. Solid catalysts' surface topography was revealed through Scanning electron microscopy SEM images Model Joel 3500 electron microscope.

Infrared spectral analysis (FTIR)

Chemical structure characterization of the solid catalysts was conducted using a Nicolet iS10 FT-IR spectrometer.

Characterization of the products

(FT-IR \& IHNMR)

All products from reactions performed in this investigation were analyzed by FT-IR in a
BIORAD-Excalibur Series FTS 3500GX system. The method of analysis varied according to the characteristics of the products. However, all of them were performed with 20 scans/min and resolution of $4 \mathrm{~cm}^{-1}$.

The analyses by hydrogen nuclear magnetic resonance ( $\left.{ }^{1} \mathrm{HNMR}\right)$ was recorded by a BRUKERAdvance $400(400 \mathrm{MHz})$ spectrometer operating at $9.4 \mathrm{~T}$, observing hydrogen at $400.13 \mathrm{MHz}$, in detoured chloroform solution $\left(\mathrm{CDC1}_{3}\right)$ using TMS as internal reference to HNMR chemical shifts.

Viscosity index measurements

Automated multi range viscometer tubes HV M472, obtained from Walter Herzog (Germany), were used to measure viscosity. Measurements were run in a Temp-Trol (Precision Scientific, Chicago, IL, USA) viscometer bath set at $40{ }^{\circ} \mathrm{C}$ and $100{ }^{\circ} \mathrm{C}$. The viscosity and viscosity index were calculated using ASTM methods D 445-97 and ASTM D 2270-93, respectively.

\section{Gel permeation chromatography (GPC)}

GPC is a type of size exclusion chromatography (SEC) that separates analytes on the basis of size. The technique is often used for the analysis of polymers. GPC Extension allows flow rate and multi-detector delay corrections and includes Narrow, Broad and Broad on Narrow calibrations.

\section{Results and Discussion}

Characterization of the prepared catalysts

XRD Pattern of $\mathrm{Cu} / \mathrm{SZ}$ catalysts

The XRD patterns obtained for the $\mathrm{SZ}, \mathrm{Cu} / \mathrm{SZ}$ (Imp) and $\mathrm{Cu} / \mathrm{SZ}$ (Sol) catalysts are illustrated in Fig. 3.The crystal size of each phase is listed in Table 1.

Applying the Scherrer's equation,

$$
\mathrm{D}=\mathrm{K} \lambda / \beta \cos \theta
$$

Where: $\mathrm{D}$ is the average crystallite diameter, $\mathrm{K}$ is the shape factor, $\theta$ is the half of position angle $\{$ Bragg angle $\}, \beta$ is the full width of half maximum FWHM of the main peak in radians,

$\lambda$ is the wave length of X-ray.

From the patterns (Fig. 3), it is clear that unloaded $\mathrm{SZ}$ and $\mathrm{Cu} / \mathrm{SZ}$ (Imp) catalysts appear more crystalline than $\mathrm{Cu} / \mathrm{SZ}$ (Sol) catalyst [22]. Figure 3a shows the XRD pattern of unloaded SZ catalyst, the peaks appearing at $2 \theta$ of $30,35,50$ and $60^{\circ}$ refer to tetragonal crystalline phase of $\mathrm{ZrO} 2[23,24]$, whereas very weak peaks appear at $2 \theta$ of 28,31 and $34^{\circ}$ indicating the presence of monoclinic phase of $\mathrm{ZrO} 2$ in low percentage.

Egypt.J.Chem. 61, No.3 (2018) 
After $\mathrm{Cu}$ loading on the $\mathrm{SZ}$ via impregnation or sol gel techniques, tetragonal phase of $\mathrm{ZrO} 2$ is the phase appeared. This result demonstrates that the addition of copper contributes to stabilizing the tetragonal zirconia [25]. The intensities of all peaks are decreased after $\mathrm{Cu}$ loading. This lowering in intensities is more significant in case of $\mathrm{Cu} / \mathrm{SZ}$ (Sol) catalyst, implying a higher dispersion of $\mathrm{Cu}$ ions in the matrix of $\mathrm{ZrO} 2$ rather than the surface of the catalyst. The same effect was observed by other researchers at high iron loadings [26]. These observations were also reported by other researchers [23-25, 27, 28]. Additional peaks are observed at $2 \theta$ of 36 and 38 corresponding to $\mathrm{CuO}$ monoclinic structure (JCPDS:80-0076 card ICSD $\neq: 067850$ ) [29-31]

In the $2 \theta$ region from 34 to 37 , the peak includes tetragonal phase of zirconia and the monoclinic structure of $\mathrm{CuO}$ and we can observe that there is a small split in the peak of $\mathrm{Cu} / \mathrm{SZ}$ (Imp) catalyst. This splitting becomes clearer in the $\mathrm{Cu} / \mathrm{SZ}$ (Sol) catalyst. The broadening and lowering of the peaks of $\mathrm{Cu} / \mathrm{SZ}$ (Sol) catalyst compared with $\mathrm{Cu} / \mathrm{SZ}$ (Imp) catalyst indicates the formation of a composite of $\mathrm{CuO}-\mathrm{ZrO} 2$.

Sulfation increases the BET area and improves the thermal stability of zirconia, preventing the reduction during high-temperature applications [32]. The TPR study for SZ prepared by sol-gel method shows that the reduction of the catalyst begins at $\sim 700^{\circ} \mathrm{C}[23,33,34]$, so $\mathrm{CuO}-\mathrm{ZrO}$ and $\mathrm{Cu}_{2} \mathrm{O}$ can't be reduced during calcination step at $600^{\circ} \mathrm{C}$. The $\mathrm{CuO}-\mathrm{ZrO}$ composite is green in color (as the color of $\mathrm{Cu} / \mathrm{SZ}(\mathrm{Sol})$ ), and may be assumed to be the main contributor for the higher activity than that of the $\mathrm{Cu} / \mathrm{SZ}$ (imp) catalyst.
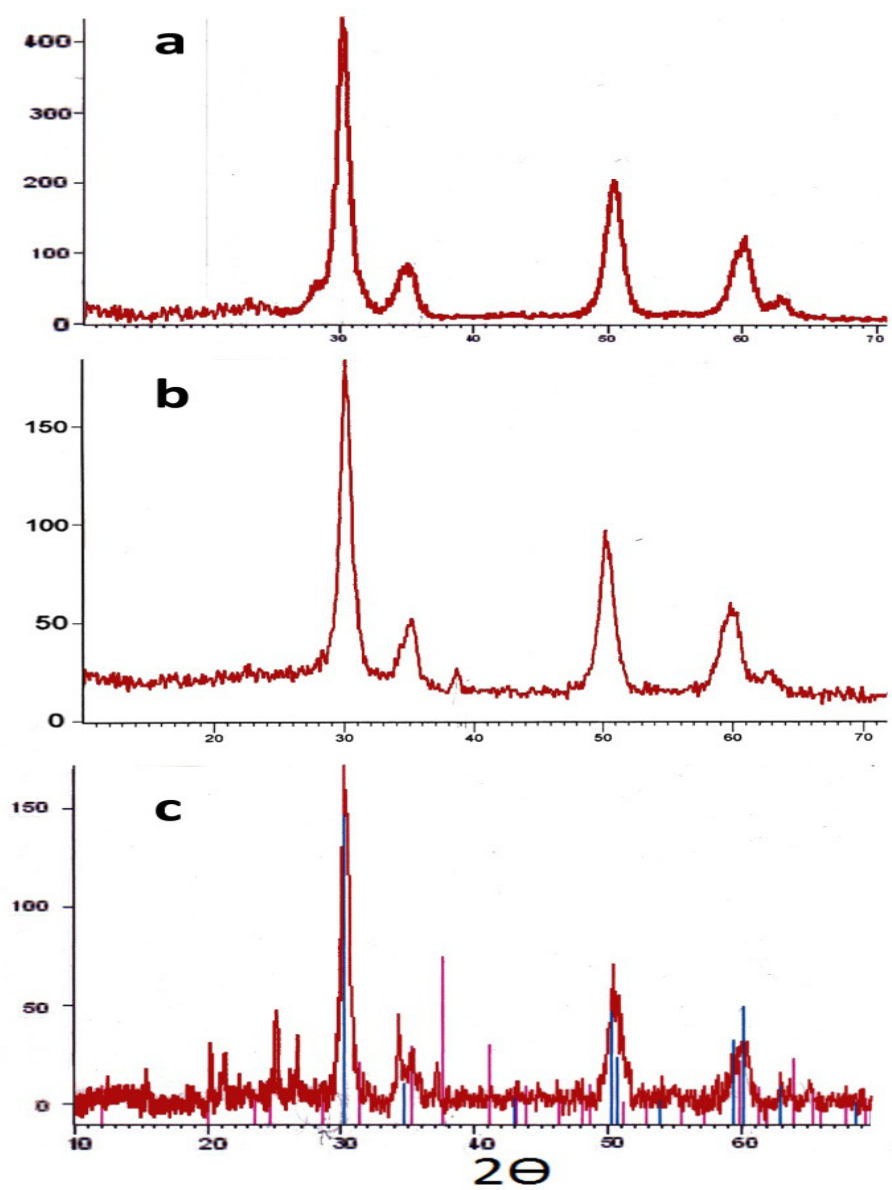

Fig. 3. XRD patterns for the prepared catalysts: (a) SZ, (b) Cu/SZ (Imp) and (c) Cu/SZ (Sol). 
Temperature Programmed Desorption (TPD)

Figure 4 shows the TPD curves obtained for the unloaded and $10 \% \mathrm{Cu}$ loaded catalysts prepared via impregnation technique $(\mathrm{Cu} / \mathrm{SZ}$ (imp)) and sol-gel technique ( $\mathrm{Cu} / \mathrm{SZ}$ (sol)). The unloaded SZ exhibits the most pronounced ammonia desorption capacity, particularly during the high temperature region $\left(400-500^{\circ} \mathrm{C}\right)$ which indicates that the metal loading achieved by both techniques (sol-gel and impregnation) has drastically decreased both density and strength of the acid sites in the unloaded catalyst all over the TPD range under study. The TPD peaks correspond to weak acid sites only $\left(50-320^{\circ} \mathrm{C}\right)$ appear in the $\mathrm{Cu} / \mathrm{SZ}$ (sol), but corresponds to somewhat higher desorption temperature $\left(50-450^{\circ} \mathrm{C}\right)$ in case of $\mathrm{Cu} /$ SZ (imp) catalyst. This succession of ammonia desorption temperature is well correlating with the strength of the prepared catalysts as follows: $\mathrm{Cu} / \mathrm{SZ}$ (sol) $<\mathrm{Cu} / \mathrm{SZ}$ (imp) ' $<\mathrm{SZ}$. This decrease in acidity may be due to the high copper loading in impregnation technique and due to interaction between copper metal and zirconium oxide in solgel technique. The amount of $\mathrm{S}$ content affected the physicochemical properties of the catalyst and its acidity, leading to different activity for esterification [35].

Surface Properties of Catalysts:

The study of the surface of the prepared

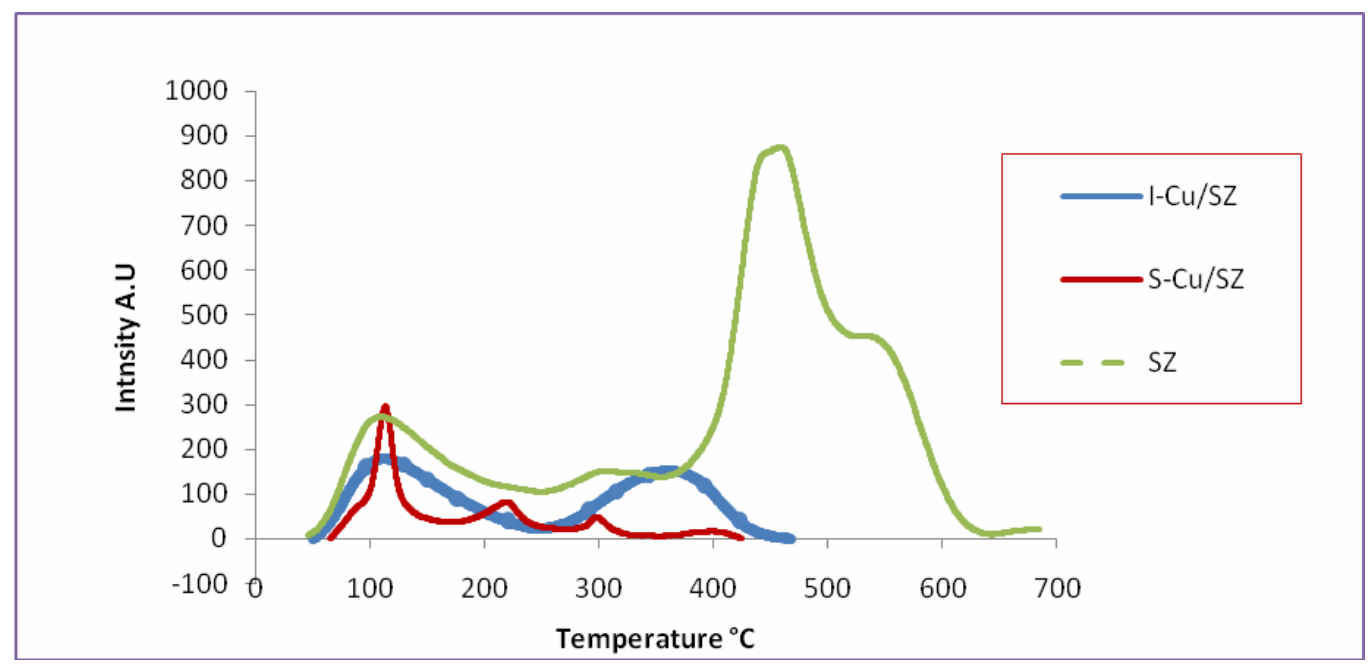

Fig. 4. $\mathrm{NH}_{3}$ temperature-programmed desorption for $\mathrm{SZ} \& \mathrm{Cu} / \mathrm{SZ}$ samples.

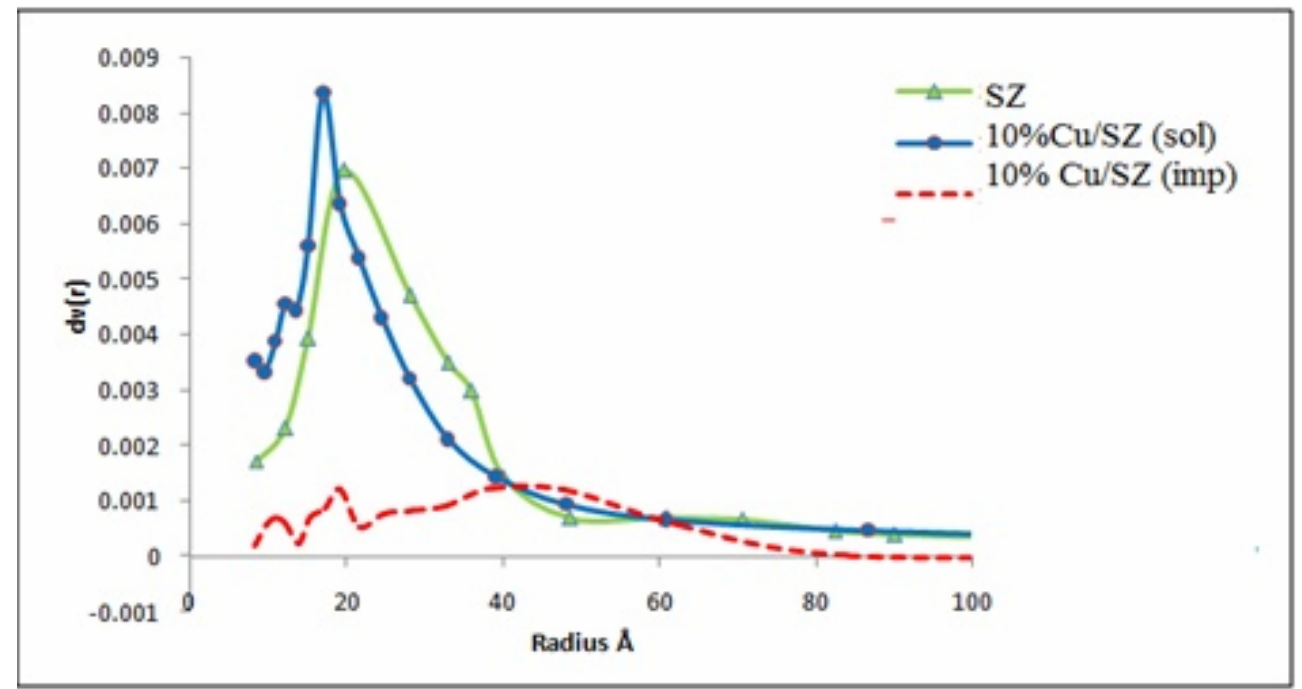

Fig. 5. Pore size distribution for $\mathrm{Cu} / \mathrm{ZS}$ catalysts.

Egypt.J.Chem. 61, No.3 (2018) 
catalysts highlights the effect of preparation on the textural properties as shown in Table 1. Roughly speaking, the textural properties are lowest for the impregnation prepared catalyst but highest for the sol-gel prepared catalyst.

The pore size distribution calculated according to the BJH computation (Fig. 5), shows that the pore size distribution for the unloaded is like solgel catalysts, but different in the pore volume.
The wider pore distribution in the range of $\sim 40$ $\AA$ is a significant property in case of impregnation prepared catalyst. This difference can be attributed to a partial filling of the pores with copper oxide particles and accordingly to the decrease of the surface area from 111 to $18 \mathrm{~m}^{2} / \mathrm{g}$ (Table 1). It is worth noting that $\mathrm{Cu} / \mathrm{SZ}$ (sol) acquired the highest activity as a result of the large surface area $\left(153.239 \mathrm{~m}^{2} / \mathrm{g}\right)$.

TABLE 1. Textural properties of the prepared catalysts.

\begin{tabular}{cccc}
\hline Catalyst & SZ & Cu/SZ(imp) & Cu/SZ (sol) \\
\hline Surface area $\left(\mathrm{m}^{2} / \mathrm{g}\right)$ & 111.8 & 18.3 & 153.239 \\
Average pore diameter $(\mathrm{nm})$ & 0.43 & 0.44 & 1.7 \\
Total pore volume (Cc/g) & 0.2 & 0.0503 & 0.186 \\
Crystal size (nm) & 22.6 & 51.8 & 16.9 \\
Color & white & Black & green \\
\hline
\end{tabular}

Scanning Electron Microscopy (SEM) analysis

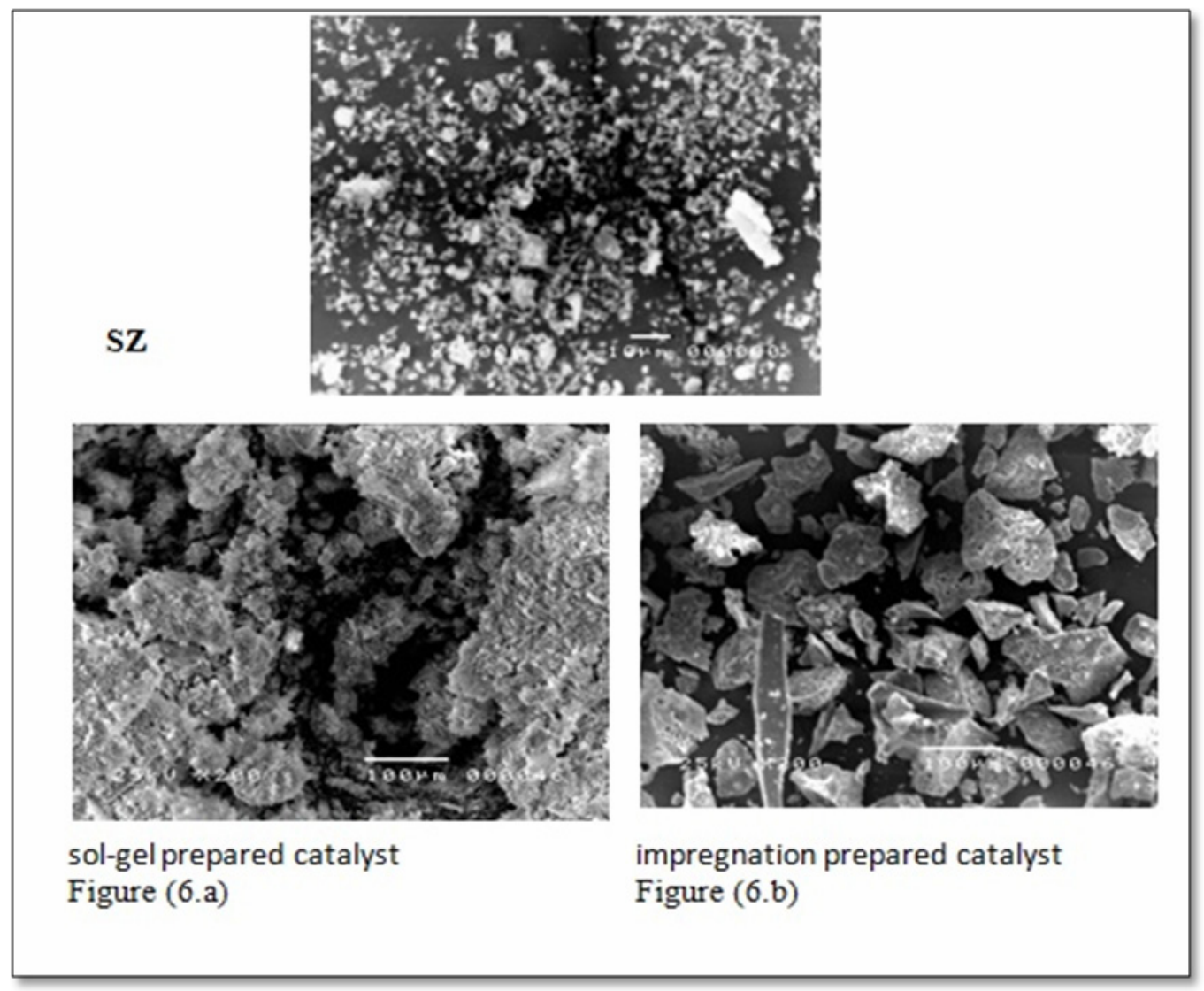

Fig. 6. Scanning Electron Microscopy (SEM) images. 
Figure 6 shows the SEM images for the prepared SZ catalysts. The current catalysts exhibit different structures and colors after calcinations. The unloaded SZ has regular particle sizes and shows a high porosity white color. The impregnated $\mathrm{Cu} / \mathrm{SZ}$ catalyst has also regular particles distribution, but possesses black coloration and low porosity. The third catalyst, $\mathrm{Cu} / \mathrm{SZ}$ (sol), is found to be of low density and spongy in nature with high porosity in green color. The black color of the impregnated sample is referred to the presence of $\mathrm{CuO}$ which has a black color, mostly on the surface of the catalyst. But, the green color of the sol-gel catalyst may due to the incorporation of the $\mathrm{Cu}$ ions in the matrix of zirconia forming the $\mathrm{CuO}-\mathrm{ZrO} 2$ composite. This result is compatible with the $\mathrm{XRD}$ results.
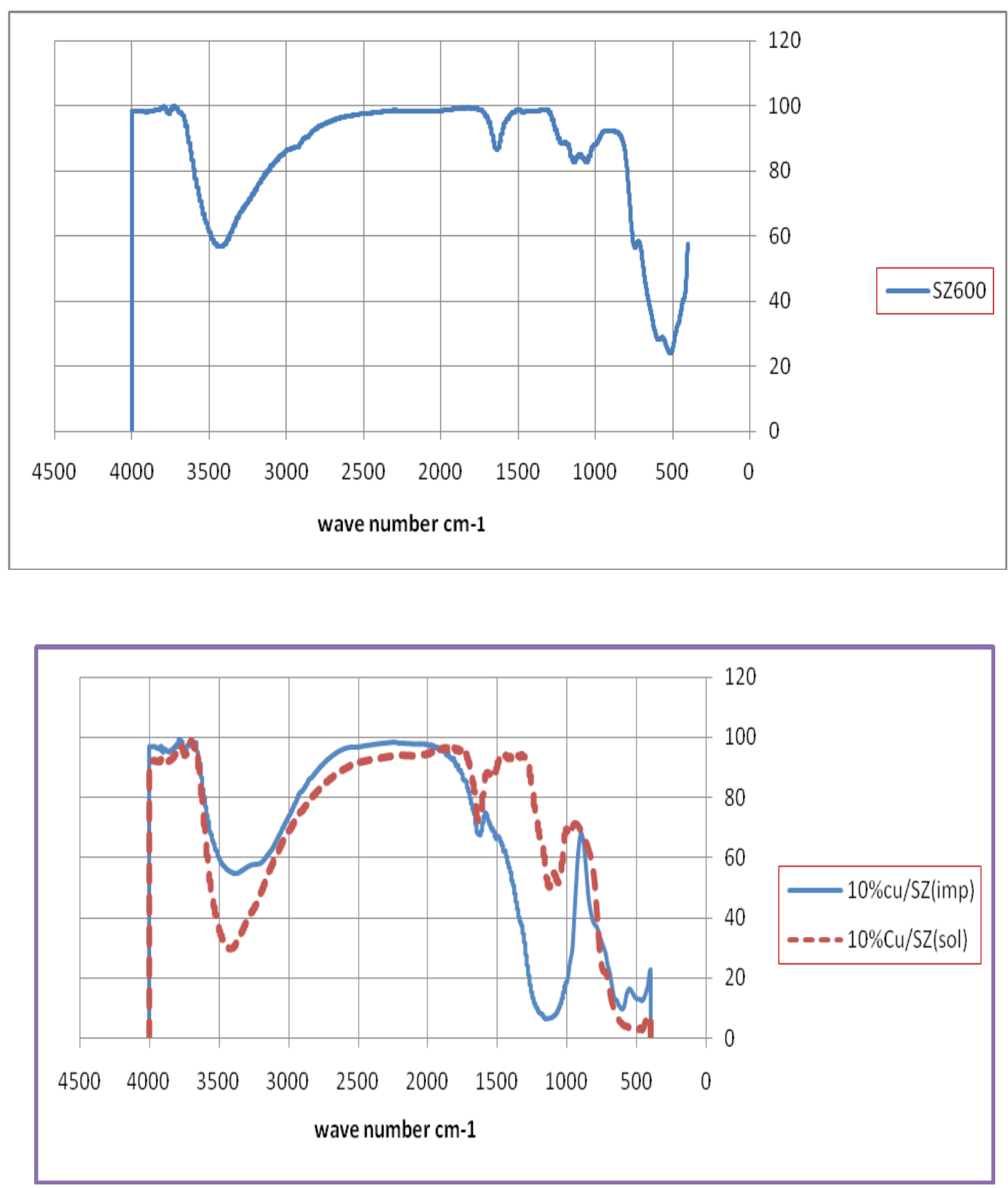

Fig. 7. IR spectra of prepared catalysts. 


\section{Infrared spectral analysis (FTIR)}

The IR spectra obtained for the prepared calcined catalysts: $\mathrm{SZ}, \mathrm{Cu} / \mathrm{SZ}$ (Imp) and $\mathrm{Cu} /$ SZ (Sol) are shown in Fig. 7. In the hydroxyl group region, stretching vibration band appearing at 3746 and $3390 \mathrm{~cm}^{-1}$ refer to the terminal $\mathrm{OH}$ group of $\mathrm{ZrOH}$ [23, 24, 36-38]. The broad band between $3000-3600 \mathrm{~cm}^{-1}$ and centered at $\sim 3400$ $\mathrm{cm}^{-1}$ is assigned to bridged $\mathrm{Zr}-\mathrm{OH}$ groups.

In case of the $\mathrm{Cu} / \mathrm{SZ}$ (Sol) catalyst, it is noticed that this broad band is of high intensity and shifted to a lower frequency (from 3390 to $3427 \mathrm{~cm}^{-1}$ ) relative to the corresponding peak. The reason for this shift is attributed mainly to the decrease of acid strength and the difference in preparation technique [39] intensities of these groups reflects the order of acidity of the different samples of catalyst. This is consistent with the TPD data in Fig. 4.

The sharp peak at $1630 \mathrm{~cm}^{-1}$ is assigned to hydroxyl deformation of adsorbed water, indicating incomplete dehydration. Also this peak affected by the degree of acidity, so, it is small in case of $\mathrm{Cu} / \mathrm{SZ}$ (Imp), and long in the second case. So, we can say that the $\mathrm{OH}$ stretching vibration band decreases by the increasing percentage loading of $\mathrm{SO}^{2-}$. This behavior may be attributed to the successive formation of $\mathrm{H}_{2} \mathrm{SO}_{4}, \mathrm{HSO}^{4-}$ and $\mathrm{SO}^{2-}$ from water sensitive $\mathrm{SO} 3$ groups. In $\mathrm{Cu} /$
SZ (sol) catalysts, the sulfate region gives sharp bands at 1128, 1054 and $977 \mathrm{~cm}^{-1}$ which are clearly attributed to S-O bond vibrations [39-41].

Moreover, the strong broadening of these peaks is attributed to the generation of an amorphous phase coating the particles of SZ as a result of the different preparation method. Sohn and Park have prepared $1.5 \% \mathrm{NiSO}_{4} / \mathrm{ZrO}_{2}$ catalyst, they reported that bands at $1270,1147,1081$ and $1034 \mathrm{~cm}^{-1}$ are attributed to the bi-dentate sulfate ion coordinated to $\mathrm{Zr}^{+4}$ and $\mathrm{Ni}^{+2}$ metals [42, 43].

The sulfate peaks for $\mathrm{Cu} / \mathrm{SZ}$ (imp) catalysts were much larger than that of the $\mathrm{Cu} / \mathrm{SZ}$ (sol) catalysts by integrating with TPD analysis, it is clear that tri-dentate sulfate ions coordinated to zirconia at low sulfur contents, while a 2-fold coordinated configuration was formed at high sulfur contents, i.e. the catalysts with low sulfur contents had a higher coordination configuration [33].

The absorption bands appearing at 430, 507 , and $606 \mathrm{~cm}^{-1}$ are attributed to the $\mathrm{Cu}-\mathrm{O}$ stretching mode in the monoclinic phase of $\mathrm{CuO}$ nanostructure for $\mathrm{Cu} / \mathrm{SZ}$ (imp). The highest intensity is observed for the $\mathrm{Cu} / \mathrm{SZ}$ (sol) catalyst at the $1000-500 \mathrm{~cm}^{-1}$ range due to introducing of $\mathrm{Cu}$ ions in the zirconia structure [44]. Peaks of zirconia at 642.3 and $449.4 \mathrm{~cm}^{-1}$ can be observed in case of impregnation [44].

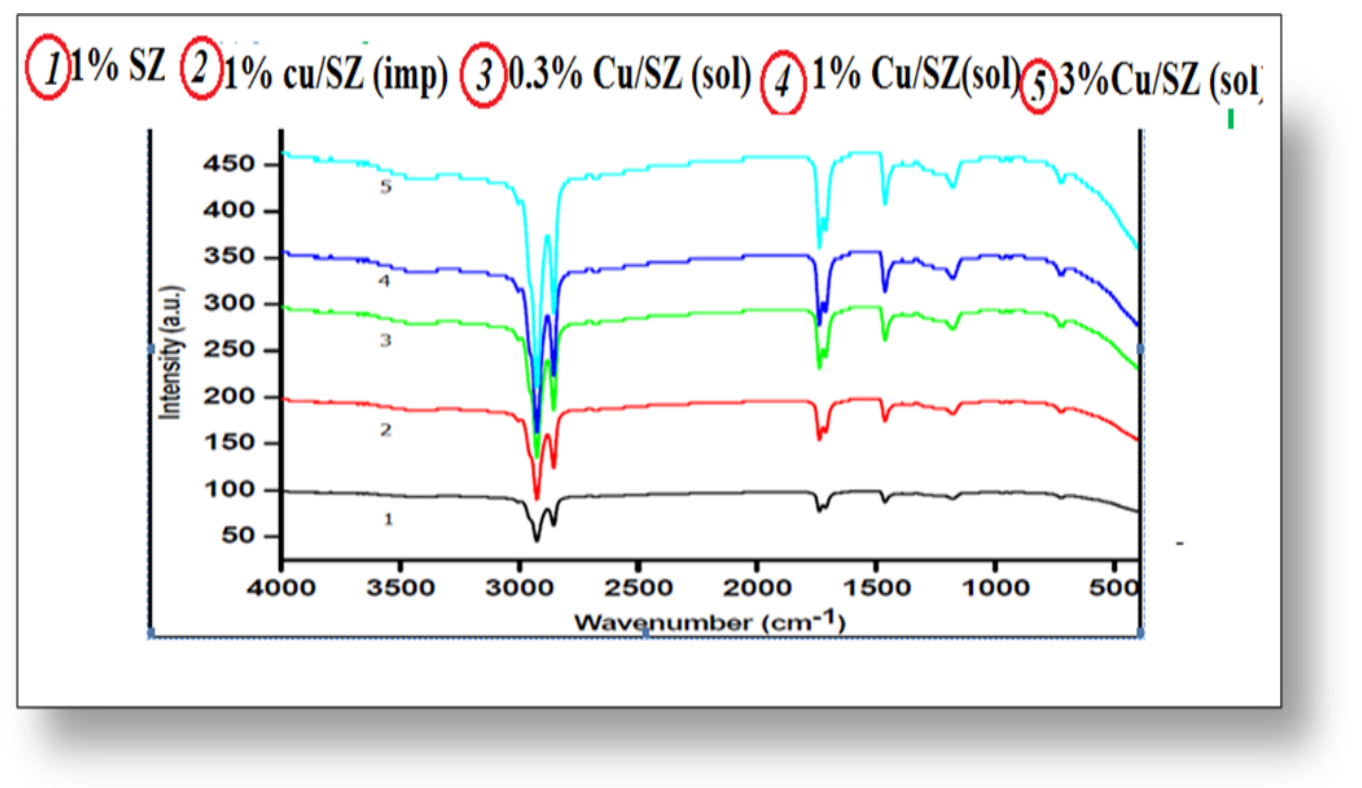

Fig. 8. FT-IR spectrum of the prepared esters. 


\section{Characterization of synthesized Ester}

The chemical structures of the prepared esters were elucidated by FT-IR analysis (Fig. 8). The absorptions at 2968 and $2856 \mathrm{~cm}^{-1}$ were assigned to the $\mathrm{CH}_{3}$ group; the absorption for $\mathrm{CH}_{2}$ group in OA at $1462 \mathrm{~cm}^{-1}$ was obtained in all spectra of the samples. On the other hand, increasing of peak intensity at $1735 \mathrm{~cm}^{-1}$ which corresponds to $\mathrm{C}=\mathrm{O}$ stretching of ester group, indicates the increase of conversion of carboxylic acid groups to ester groups by increasing the concentration of $\mathrm{Cu} / \mathrm{SZ}$ catalyst. Furthermore, the appearance of broad peak at $1176 \mathrm{~cm}^{-1}$ in all spectra of the samples, which corresponds to $\mathrm{C}-\mathrm{O}-\mathrm{C}$ vibration, indicates the formation of ester in the prepared oils by using any of the prepared catalysts. The absence of the broad peak at $3450 \mathrm{~cm}^{-1}(\mathrm{OH}$ stretching of $\mathrm{COOH}$ group) can be also attributed to formation of ester group and consumption of all hydroxyl groups during the esterification reaction.

TABLE 2. Pour point (PPT), Flash point (FP), Viscosity index (VI), Apparent Viscosity (AV), Molecular weight (Mwt) and Percentage yield values of synthetic ester oils

\begin{tabular}{|c|c|c|c|c|c|c|c|c|c|c|c|}
\hline San & & Cotolunt & Catalyst & PPT, & FP, & $\begin{array}{r}\text { Kin } \\
\text { vis } \\
\text { (m }\end{array}$ & $\begin{array}{l}\text { natic } \\
\text { sity } \\
2 / s \text { ) }\end{array}$ & $\mathbf{V I}_{\mathbf{T}}$ & AV, & Yield, & Mvot \\
\hline Alcohol & $\begin{array}{l}\text { Fatty } \\
\text { Acid }\end{array}$ & & & & & $40^{\circ} \mathrm{C}$ & $100^{\circ} \mathrm{C}$ & & & & \\
\hline \multirow{5}{*}{ 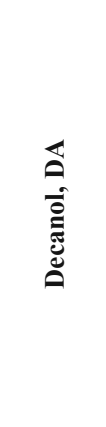 } & \multirow{5}{*}{ 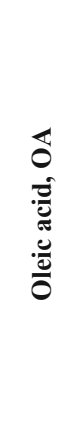 } & $\mathrm{SZ}$ & 1.0 & -9 & 172 & 15.9 & 4.0 & 157 & 26.0 & 85.5 & 1129 \\
\hline & & $\begin{array}{c}10 \% \mathrm{Cu} / \mathrm{SZ} \\
\text { (imp) }\end{array}$ & 1.0 & -6 & 185 & 14.1 & 3.9 & 189 & 21.0 & 89.1 & 959 \\
\hline & & $\begin{array}{c}10 \% \mathrm{Cu} / \mathrm{SZ} \\
\text { (sol) }\end{array}$ & 1.0 & -6 & 126 & 13.3 & 3.3 & 119 & 20.0 & 93.9 & 1013 \\
\hline & & $\begin{array}{c}10 \% \mathrm{Cu} / \mathrm{SZ} \\
(\mathrm{sol})\end{array}$ & 0.3 & -9 & 203 & 12.0 & 3.7 & 223 & 20.8 & 99.8 & 1042 \\
\hline & & $\begin{array}{c}10 \% \mathrm{Cu} / \mathrm{SZ} \\
(\mathrm{sol})\end{array}$ & 3.0 & -9 & 137 & 11.2 & 3.1 & 144 & 19.2 & 89.5 & 1015 \\
\hline
\end{tabular}

\section{Product parameters}

The molecular weights of the prepared esters were determined using the GPC technique described in the experimental section. The resultant molecular weights are listed in Table 2.

The ability of a material to remain in the liquid state at low temperatures represents a quality base for number of industrial materials, such as surfactants, biolubricants, and fuels. The cold flow property of plant oils is extremely poor and limits their use at low operating temperatures, especially those used as automotive and industrial fluids. Plant oils have a tendency to form macrocrystalline structures at low temperatures through uniform stacking of the ester backbone [45]. Such macrocrystals restrict the easy flow of the system due to loss of kinetic energy of individual molecules during self-stacking. Cold flow properties of these samples were determined using their pour points. In practice, the usable liquid range is limited by the pour point (PP) at low temperatures and the flash point at high temperatures. The PP should be low to ensure that the lubricant is pumpable when the equipment is started from extremely low temperatures. The flash point should be high to allow the safe operation and minimum volatilization at the maximum operating temperature. For the most demanding applications, such as aviation jet engine lubricants, an effective liquid range over $300{ }^{\circ} \mathrm{C}$ may be required [46].

The oleic acid synthetic mono-esters described above were screened for low temperature behavior through determination of their pour point (PP). Therein, an improvement of the cold flow behavior of the prepared esters was realized.

The efficiency of the biolubricant in reducing friction and wear is greatly influenced by its viscosity. The viscosity must always be high enough to keep sufficient oil film between the moving parts. The Viscosity Index (VI) is an arbitrary measure for the change of viscosity with 
variation in temperature. The lower the VI, the greater the viscosity of the oil changes with temperature and vice versa. The pour point (PPT), flash point (FP), viscosity index (VI), apparent viscosity $(\mathrm{AV})$ and percentage yield values of synthetic ester oils were evaluated and recorded in Table 2.

An important property of lubricants is their ability to maintain a stable lubricating film at the metal contact zone. Chain length of the fatty acid of plant oils is known to provide excellent lubricity due to their ester functionality where, the polarity of the ester molecule attached to metal surface allows a monolayer film formation with the non-polar end of fatty acid chains sticking away from the metal surface. The ester structures offer active oxygen sites that trigger binding on the metal surface forming a protective film which builds further with time to reduce friction $[47,48]$.

\section{Conclusion}

The difference in preparation techniques revealed significant effects on all prepared catalysts 'characterization. The preparation by sol-gel technique produces a stable, high surface area catalyst with low-to medium acidity which is suitable to apply in esterification reaction that needs this degree of acidity and high surface area. This method eliminates formation of surface sulfates which can, in the presence of water produced from esterification reaction, causes many problems. So, it is more suitable to apply sol-gel technique in the preparation, to achieve high yield and quality of lubricating oil.

\section{References}

1. Heikal, E.K., Elmelawy, M.S., Khalil, S.A. Elbasuny, N.M., Manufacturing of enviro,ment friendly biolubricants from vegetable oils. Egyptian Journal of Petroleum 26, 53-59 (2017).

2. Chandu, S., Madankara, Dalaia, A. K., Naik, S.N. "Green synthesis of biolubricant base stock from canola oil" Industrial Crops and Products 44,139144 (2013).

3. Oha, J., Yanga, S., Kima, C., Choi, I., Kimb, J. H., Hyunjoo Leea, Synthesis of biolubricants using sulfated zirconia catalysts. Applied Catalysis A: General 455,164-171 (2013).

4. Vasudevan, P.T. and Briggs, M. Biodiesel. production - current state of the art and challenges. J. Ind. Microbiol. Biotechnol; 35, 421-430 (2008).
5. Dorado, M.P., Ballesteros, E., Mittelbach, M., and Lopez, F.J. Synthesis of Biodiesel from SecondUsed Cooking Oil. Energy Fuels; 18, 1457-1462 (2004).

6. Padmajaa, K.V., Raoa, B.V.S.K., Reddya, R.K., Bhaskar, P.S., Singhb, A.K., Prasada , R. B.N.,* 10-Undecenoic acid-based polyol esters as potential lubricant base stocks. Industrial Crops and Products 35, 237-240 (2012).

7. Argyle, M.D. and Bartholomew, C.H., Heterogeneous Catalyst Deactivation and Regeneration: A Review. Catalysts, 5, 145-269 (2015); doi:10.3390/catal5010145.

8. Zhou, Y., , Noshadi, I. , Ding, H., Liu, J., Parnas, R. S. , Clearfield, A., Xiao, M., Meng ,Y. and Sun, L., Solid Acid Catalyst Based on Single-Layer $\alpha$-Zirconium Phosphate Nanosheets for Biodiesel Production via Esterification. Catalysts, 8, 17 (2018).

9. Lambaa, R., Sarkarb, S. , Kumar, S., Solid acid catalyst supported synthesis and fuel properties of ethyl decanoate. Fuel 222, 98-104 (2018).

10. Chen, S. S., Maneerung, T., Tsang, D.C.W., Ok, Y. S., Wang, C., Valorization of biomass to hydroxymethylfurfural, levulinic acid, and fatty acid methyl ester by heterogeneous catalysts. Chemical Engineering Journal 328, 246-273 (2017).

11. Satyarthi, J.K., Srinivas, D. and Ratnasamy, P. Hydrolysis of vegetable oils and fats to fatty acids over solid acid catalysts. Applied Catalysis A: General 391, 427-435 (2011).

12. Satyarthi, J.K., Srinivas, D. and Ratnasamy, P. Influence of Surface Hydrophobicity on the Esterification of Fatty Acids over Solid Catalysts. Energy Fuels; 24, 2154-2161 (2010).

13. Munguiaa, D.A.C., Tzompantzib, F., GutiérrezAlejandrec, A., Ricoa, J.L. and González, H., ZnAl-Zr hydrotalcite-like compounds activated at low temperature as solid base catalyst for the transesterification of vegetable oils. Energy Procedia 142, 582-589 (2017).

14. Mongea, J.A., Bouchra El Bakkalia, Trautweina, G., Reinosob, S., Zirconia-supported tungs to phosphoric heteropoly acid as heterogeneous acid catalyst for biodiesel production. Applied Catalysis B: Environmental 224, 194-203 (2018).

15. Figueiredo, K. C. S., Salim, V. M. M. and 
Borges, C. P.. Ethyl oleate production by means of pervaporation-assisted esterification using heterogeneous catalysis. Brazilian Journal of Chemical Engineering; 27 (04), 609 - 617 (2010).

16. Boffito, D.C., Crocellà, V., Pirola, C., Neppolian, B., Cerrato, G., Ashokkumar, M. and Bianchi, C.L. Ultrasonic enhancement of the acidity, surface area and free fatty acids esterification catalytic activity of sulphated $\mathrm{ZrO} 2-\mathrm{TiO} 2$ systems a. Journal of Catalysis 297, 17-26 (2013).

17. Kiss, A. A., Dimian, A. C., and Rothenberg, G. Solid acid catalysts for biodiesel production towards sustainable energy. Adv. Synth. Catal.; 348, 75-81 (2006).

18. Tichit, D., Coq, B., Amendarize, H. and Figuéras, F. One-step sol-gel synthesis of sulphated-zirconia catalysis. Catal. Lett. ; 38, 109 1(996).

19. Berrios, M., Siles, J. Martin, M.A., Martin, A.A. kinetic study of the esterification of free fatty acids in sunflower oil. Fuel; 86, 2383-2388 (2007)

20. Lee, D., and Lee, K. Heterogeneous Solid Acid Catalysts for Esterification of Free Fatty Acids. Catal Surv Asia; 18, 55-74 (2014).

21. Patrick, J. Barrie. Analysis of temperature programmed desorption (TPD) data for the characterisation of catalysts containing a distribution of adsorption sites. Phys. Chem. Chem. Phys. ; 10, 1688-1696 (2008), DOI: 10.1039/B717430F.

22. Turapan, S., Yotkamchornkun, C., and Nuithitikul, K. Esterification of free fatty acids in crude palm oil with sulphated zirconia: Effect of calcinations temperature. Journal of World Academy of Science, Engineering And Technology; 41, 520-524 (2010).

23. Aboul-Gheit, A. K., El-Desouki, D. S., AbdelHamid, S. M., Ghoneim, S. A., Ibrahim, A. H., and Gad, F.K. Sulfated Zirconia Catalysts for Low Temperature Isomerization of n-Pentane. Egypt. J. Chem. 55 (5), 509- 527 (2012).

24. Turapan, S., Yotkamchornkun, C., and Nuithitikul, $\mathrm{K}$. Esterification of free fatty acids in crude palm oil with sulphated zirconia: Effect of calcinations temperature. Journal of World Academy of Science, Engineering And Technology; 41, 520-524 (2010).

25. Sunaja Devi, K. R. and Jayashree, S. Eco Friendly Nitration of Toluene using Modified Zirconia. Bulletin of Chemical Reaction Engineering \& Catalysis, 7 (3), 205 - 214 (2013).
26. Spielbauer D, Mekhemer G.A.H., and Knözinger H. Acid properties of sulphated Zirconia. Catal Lett; 36, 5 (1996).

27. Suja, A.H., and Sugunan, S. Iron Promoted Sulphated Zirconia Systems As Efficient Catalysts For Phenol Hydroxylation. Bull. Catal. Soc. India; 2, 194-203 (2003).

28. Romero, A. O., de Correa, C. M., and Lodoño, F. B. Preparation and characterization of Mg-modified zirconias as catalysts for the direct synthesis of dimethyl carbonate (DMC). Rev. Fac. Ing. Univ. Antioquia; 57, 14-22 (2011).

29. Yoon, H.A. (1996) The structures and dynamics of atomic and molecular adsorbates on metal surfaces by scanning tunneling microscopy and low energy electron diffraction, Ph.D. Thesis. University of California (1996).

30. Lanje, A.S., Sharma, S.J., Pode, R.B. and Ningthoujam, R.S. Synthesis and optical characterization of copper oxide nanoparticles. Advances in Applied Science Research; 1(2), 36-40 (2010).

31. Zhao, Y., Tao, K. and Wan, H. L. Effect of zirconia phase on the reduction behavior of highly dispersed zirconia-supported copper oxide. Catalysis Communications 5, 249-252 (2004).

32. Khan, M.A., Ullah, M., Iqbal, T., Mahmood, H., Khan, A.A., Shafique, M., Majid, A., Ahmed, A. and Khan, N.A. Surfactant Assisted Synthesis of Cuprous Oxide $\left(\mathrm{Cu}_{2} \mathrm{O}\right)$ Nanoparticles via Solvothermal Process. Nanoscience and Nanotechnology Research; 3 (1), 16-22 (2015).

33. Norman, C.J., Goulding, P.A. and McAlpine, I. Role of anions in the surface stabilization of zirconia. Catal Today; 20, 313-322 (1994).

34. Witoon, T., Permsirivanich, T., Kanjanasoontorn, N., Akkaraphataworn, C., Seubsai, A., Faungnawakij, K., Warakulwit, C., Chareonpanich, M., and Limtrakul, J. Direct synthesis of dimethyl ether from $\mathrm{CO}_{2}$ hydrogenation over $\mathrm{Cu}-\mathrm{ZnO}-\mathrm{ZrO}_{2} / \mathrm{SO}_{4}{ }^{2-}-\mathrm{ZrO}_{2}$ hybrid catalysts: effects of sulfur-to-zirconia ratios. Catal. Sci. Technol 5, 2347-2357 (2015)..

35. Prasetyoko, D., Ramli, Z., Endud, S. and Nur, H. Structural and Acidity Studies of Sulfated Zirconia Prepared from Zirconium Sulfate. MajalahI PTEK; 17(2), 40-48 (2006).

36. Jinho, O., Sungeun, Y., Chanyeon, K., Inchang, Ch., Jae, H. K. and Hyunjoo, L. Synthesis of 
biolubricants using sulfated zirconia catalysts. Applied Catalysis A: General; 455, 164- 171 (2013).

37. Föttinger, K., Halwax, E., and Vinek, H. Deactivation and regeneration of Pt containing sulfated zirconia and sulfated zirconia. Appl. Catal. A: General; 301, 115-122 (2006).

38. Armendariz, H., Sanchez Sierra, C., Figueras, F., Coq, B., Mirodatos, C., Levebre, F., and Tichit., D. Hydrogen Exchange between Sulfated Zirconias and per Deutero- Benzene as Characterization of the Surface Acidity. J. Catal.; 171, 85-92 (1997).

39. Kustov, L.M., Kazansky, V.B., Figueras, F. and Tichit, D. Investigation of the Acidic Properties of $\mathrm{ZrO}_{2}$ Modified by $\mathrm{SO}_{4}^{2-}$ Anions. J. Catal.; 150, 143-149 (1994).

40. Deshmane, V.G. and Adewuyi., Y.G. Mesoporous Nanocrystalline Sulfated Zirconia Synthesis and Its Application for FFA Esterification in Oils. Appl. Catal. A: Gen.; 462-463, 196-206 (2013).

41. Radwan, D., Saad, L., Mikhail, S. and Selim., S.A. Catalytic Evaluation of Sulfated Zirconia Pillared Clay in N-hexane isomerization. Journal of Applied Sciences Research; 5 (12), 2332-2342 (2009).

42. Platero, E.E., Mentruit, M.P., Arean, C.O. and Zecchina, A. FTIR studies on the acidity of sulfated zirconia prepared by thermolysis of zirconium sulfate J. Catal.; 162, 268 (1996).
43. Cerrato, G. Morterra, C. Delgado, M.R., Arean., C.O., Signoretto, M., Somma, F. and Pinna, F. Ga.promoted sulfated zirconia systems. II. Surface features and catalytic activity. Microporous and Mesoporous Materials; 94, 40-49 (2006).

44. Sohn, J. R. and Park, E. H. Characterization of nickel sulfate supported on zirconia and its acidic properties. J. Ind. Eng. Chem.; 6 (5), 297-304 (2000).

45. Bouazizi, N., Bargougui, R., Oueslati, A. and Benslama, R. Effect of synthesis time on structural, optical and electrical properties of $\mathrm{CuO}$ nanoparticles synthesized by reflux condensation method Adv. Mater. Lett.; 6 (2), 158-164 (2015).

46. Kleinova', A., Fodran, P., Brnc`alova', L. and Cvengros $\_$J. Substituted esters of stearic acid as potential lubricants. Biomass Bioenergy; 32, 366-371 (2008).

47. Salimon J., Salih, N. and Yousif, E. Biolubricants: raw materials, chemical modifications and environmental benefits. Eur. J. Lipid Sci. Technol.; 112, 519-530 (2010).

48. Salimon, J., Salih, N. and Yousif, E. Improvement of pour point and oxidative stability of synthetic ester base stocks for biolubricant applications Arabian Journal of Chemistry; 5, 193-200 (2012).

49. Jinho, O., Sungeun, Y., Chanyeon, K., Inchang, Ch., Jae, H.K. and Hyunjoo, L., Synthesis of biolubricants using sulfated zirconia catalysts. Applied Catalysis A: General; 455, 164- 171 (2013).

(Received 8/3/2018; accepted $2 / 5 / 2018)$ 


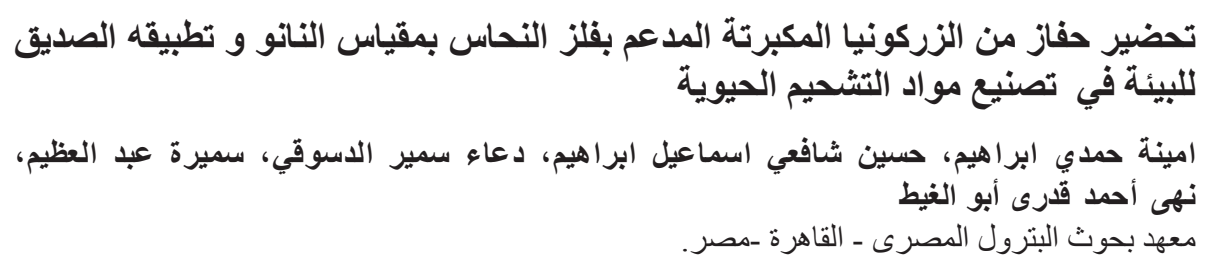

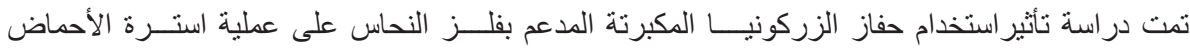

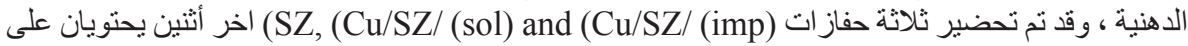

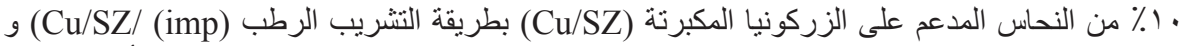

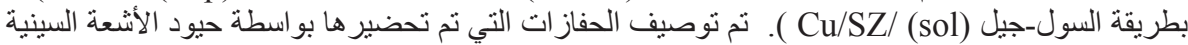

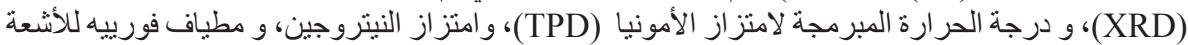

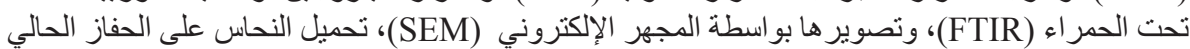

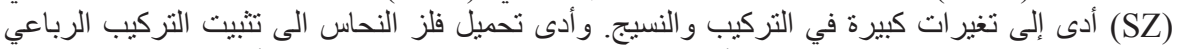

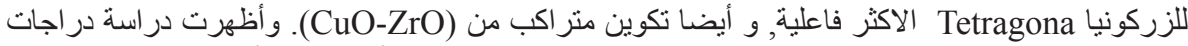

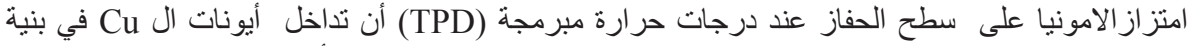
الزركونيا (Zirconia lattice) بطريقة سول-جل قد تسبب في خفض الحامضية أكثر مما يفعل طريقة التشريب ائري

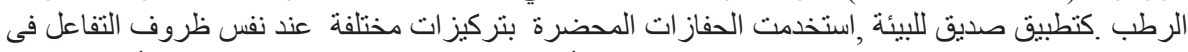

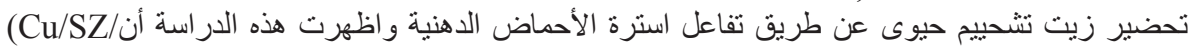
(sol)

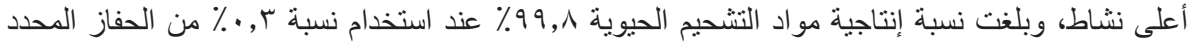

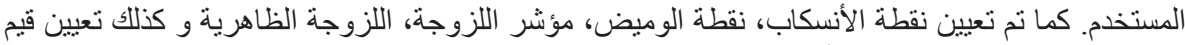

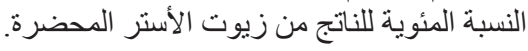

